\title{
TWO FLUORO COMPOUNDS OF MAIN GROUP ELEMENTS: SYNTHESIS, CHARACTERIZATION, THEORETICAL AND SPECTROSCOPIC STUDY
}

\author{
A. Lashgari ${ }^{1}$, S. Ghammamy ${ }^{1}$, R. Ramirez-Tagle ${ }^{2}$, G. Salgado-Moran ${ }^{3}$ \\ ${ }^{1}$ Department of Chemistry, Faculty of Science, Imam Khomeini International University, Qazvin, Iran \\ ${ }^{2}$ Universidad Bernardo O'Higgins, Laboratorio de Bionanotecnologia, Santiago, Chile \\ E-mail: rramirez@ubo.cl \\ ${ }^{3}$ Facultad de Ciencias Exactas, Departamento de química, Universidad Andrés Bello, sede Concepción, \\ Concepción, Chile
}

Received November, 25, 2014

\begin{abstract}
Two new compounds of fluorine: $\left(\mathrm{C}_{2} \mathrm{H}_{5}\right)_{4} \mathrm{~N}\left[\mathrm{I}_{2} \mathrm{~F}\right]$ and $\left(\mathrm{C}_{2} \mathrm{H}_{5}\right)_{4} \mathrm{~N}\left[\mathrm{Br}{ }_{2} \mathrm{~F}\right]$ have been easily synthesized in a nearly quantitative by a direct reaction of $\left(\mathrm{C}_{2} \mathrm{H}_{5}\right)_{4} \mathrm{NF}, \mathrm{I}_{2}$ and $\mathrm{Br}_{2}$. The products were isolated and characterized by elemental analysis and spectroscopic methods such as: Fourier transform infrared spectroscopy (FTIR) and ultraviolet-visible spectroscopy (UV-Vis). These compounds have been studied with the Scalar ZORA relativistic level of theory using the ADF program package. The molecular parameters, and vibrational spectra were calculated. The excitation energies were found by time-dependent perturbation density functional theory (TDDFT). Molecule optimization, frequencies and excitation energies were calculated with standard Slatertype-orbital (STO) basis sets with triple-zeta quality double plus polarization functions (TZ2P) for all atoms. The FTIR, UV-Vis spectra and assignment of principal transitions and total density of state (TDOS) were extracted using the GaussSum 2.2 program. The comparison between experimental and calculated values shows that the experimental results correlate well with the predicted data.
\end{abstract}

DOI: $10.15372 / \mathrm{JSC} 20150807$

K e y w o r d s: synthesis, halo compounds, main group elements, computation, spectroscopic studies.

\section{INTRODUCTION}

There is a growing interest in the study of main group element halo compounds. The unique characteristics of halide impart an uncommon reactivity to halide-fluoride bonds, which can be exploited in preparative inorganic chemistry or in catalysis. In recent years there has been a prodigious deal of interest in halo compounds. This is because of the significant prerequisites for halo compounds to be valuable, which are flexibility, discrimination and operational simplicity. One of the main reactions for synthesis of halo compounds is the reaction of tetraalkylammonium salts with a halide source compounds. By using these type of reagents several unique halo compounds of the main group elements can be produced, such as $\left(\mathrm{CH}_{3}\right)_{4} \mathrm{~N}\left[\mathrm{PF}_{4}\right],\left(\mathrm{CH}_{3}\right)_{4} \mathrm{~N}\left[\mathrm{SeF}_{5}\right],\left(\mathrm{C}_{4} \mathrm{H}_{9}\right)_{4} \mathrm{~N}\left[\mathrm{PbCl}_{2} \mathrm{~F}\right],\left(\mathrm{C}_{4} \mathrm{H}_{9}\right)_{4} \mathrm{~N}\left[\mathrm{PbI}_{2} \mathrm{~F}\right]$, $\left(\mathrm{CH}_{3}\right)_{4} \mathrm{~N}\left[\mathrm{IF}_{8}\right]$ and such as $\left(\mathrm{CH}_{3}\right)_{4} \mathrm{~N}\left[\mathrm{MoO}_{3} \mathrm{~F}\right],\left(\mathrm{CH}_{3}\right)_{4} \mathrm{~N}\left[\mathrm{CrO}_{3} \mathrm{~F}\right],\left(\mathrm{CH}_{3}\right)_{4} \mathrm{~N}\left[\mathrm{MoF}_{7}\right],\left(\mathrm{CH}_{3}\right)_{4} \mathrm{~N}\left[\mathrm{WF}_{7}\right]$, $\left(\mathrm{CH}_{3}\right)_{4} \mathrm{~N}\left[\mathrm{ReOF}_{6}\right]$, and $\left(\mathrm{CH}_{3}\right)_{4} \mathrm{~N}\left[\mathrm{WO}_{3} \mathrm{~F}\right][1-6]$.

By using tetraalkylammonium salts numerous halo compounds of transition metal elements were produced, such as $\left(\mathrm{CH}_{3}\right)_{4} \mathrm{~N}\left[\mathrm{I}_{2} \mathrm{Br}\right]$, tetramethylammoniumbrominediiodate (TMABDI), $\left(\mathrm{C}_{4} \mathrm{H}_{9}\right)_{4} \mathrm{~N}[\mathrm{SBr}]$, tetrabuthylammoniumbromosulfide (TBABS), $\left(\mathrm{C}_{2} \mathrm{H}_{5}\right)_{4} \mathrm{~N}\left[\mathrm{I}_{2} \mathrm{Br}\right]$, tetraethylammoniumbromodiiodate

(C) Lashgari A., Ghammamy S., Ramirez-Tagle R., Salgado-Moran G., 2015 
(TAABDI), $\left(\mathrm{CH}_{3}\right)_{4} \mathrm{~N}\left[\mathrm{I}_{2} \mathrm{Cl}\right]$, tetramethylammoniumchlorinediiodate (TMACDI). There are several incentives for choosing $\left(\mathrm{C}_{2} \mathrm{H}_{5}\right)_{4} \mathrm{~N}^{+}$as the counter ion. One reason is that quaternary ions such as tetraethylammonium are frequently used as phase transfer catalysts.

In the present study we synthesized two new compounds of fluorine: $\left(\mathrm{C}_{2} \mathrm{H}_{5}\right)_{4} \mathrm{~N}\left[\mathrm{I}_{2} \mathrm{~F}\right]$ and $\left(\mathrm{C}_{2} \mathrm{H}_{5}\right)_{4} \mathrm{~N}\left[\mathrm{Br}_{2} \mathrm{~F}\right]$. The products were separated and characterized by elemental analysis, spectroscopic and theoretical methods such as Fourier transform infrared spectroscopy (FTIR) and ultraviolet-visible spectroscopy (UV-Vis).

\section{EXPERIMENTAL}

Materials and methods. Acetonitrile (Fluka, P. A.) was distilled several times from phosphorus pentoxide before use, thereby reducing its water content to $<4 \mathrm{ppm}$. Tetraethylammonium fluoride was bought from Merck. $\mathrm{I}_{2}$ and $\mathrm{Br}_{2}$ (Merck, $\mathrm{P}$. A.) were used without additional purification. Solvents were cleansed by common approaches. Infrared (IR) spectra were recorded as $\mathrm{KBr}$ discs on a Shimadzu model 420 spectrophotometer. The UV-Vis quantities were completed on a Uvicon model 922 spectrometer. The percent composition of elements was obtained from the Department of Chemistry, Micro analytical Laboratories, OIRC, Tehran.

General procedure. Synthesis of tetraethylammonium flourodiiodate (TAAFDI), $\left(\mathbf{C}_{2} \mathbf{H}_{5}\right)_{4} \mathbf{N}\left[\mathbf{I}_{2} \mathbf{F}\right]$. Solid powder tetraetylammonium fluoride $(0.2 \mathrm{~g}, 1.1 \mathrm{mmol})$ was added to a solution of $\mathrm{I}_{2}(0.31 \mathrm{~g}, 1 \mathrm{mmol})$ in $\mathrm{MeCN}$ and stirred at room temperature until the black color of the solution changed to red (equation (1)). The solution was stirred continuously for $8 \mathrm{~h}$. The solvent was then evaporated, the solid washed with ether and dried at room temperature. $M_{\mathrm{p}} 102-104{ }^{\circ} \mathrm{C}$. Anal. Calc. for $\left(\mathrm{C}_{8} \mathrm{H}_{20} \mathrm{NI}_{2} \mathrm{~F}\right)(\%)$ : C 23.84, H 5, N 3.47; found (\%): C 23.8, H 5.00, N 3.475. UV-Vis and IR were all consistent with the TAAFDI structure.

$$
\left(\mathrm{C}_{2} \mathrm{H}_{5}\right)_{4} \mathrm{NF}+\mathrm{I}_{2} \rightarrow\left(\mathrm{C}_{2} \mathrm{H}_{5}\right)_{4} \mathrm{~N}\left[\mathrm{I}_{2} \mathrm{~F}\right] .
$$

Synthesis of tetraethylammonium fluorodibromide (TAAFDB), $\left(\mathrm{C}_{2} \mathrm{H}_{5}\right)_{4} \mathbf{N}\left[\mathrm{Br}_{2} \mathrm{~F}\right]$. Tetraethylammonium fluorodibromide, $\left(\mathrm{C}_{2} \mathrm{H}_{5}\right)_{4} \mathrm{~N}\left[\mathrm{Br}_{2} \mathrm{~F}\right]$ was prepared by dissolving $\mathrm{Br}_{2}(0.25 \mathrm{~g}, 1 \mathrm{mmol})$ in $\mathrm{MeCN}$ and addition of this solution to a solution of tetraethylammonium fluoride $(0.26 \mathrm{~g}, 1.1 \mathrm{mmol})$ in $\mathrm{MeCN}$ and stirring at room temperature until the red color changed to orange (equation (2)). The solution was stirred for $8 \mathrm{~h}$. The solvent was then evaporated, the solid washed with ether and dried at room temperature. $M_{\mathrm{p}}$ : $64.7-66^{\circ} \mathrm{C}$. For $\left(\mathrm{C}_{8} \mathrm{H}_{20} \mathrm{NBr}_{2} \mathrm{~F}\right)(\%)$ : C 31.09, $\mathrm{H} 6.522, \mathrm{~N} 4.532$; found (\%): $\mathrm{C} 31.1, \mathrm{H}$ 6.53, N 4.54. UV-Vis and IR were all consistent with the proposed TAAFDB structure.

$$
\left(\mathrm{C}_{2} \mathrm{H}_{5}\right)_{4} \mathrm{NF}+\mathrm{Br}_{2} \rightarrow\left(\mathrm{C}_{2} \mathrm{H}_{5}\right)_{4} \mathrm{~N}\left[\mathrm{Br}_{2} \mathrm{~F}\right] \text {. }
$$

Computational methods. The geometry optimizations and computations of the characteristics of $\left(\mathrm{C}_{2} \mathrm{H}_{5}\right)_{4} \mathrm{~N}\left[\mathrm{I}_{2} \mathrm{~F}\right]$ and $\left(\mathrm{C}_{2} \mathrm{H}_{5}\right)_{4} \mathrm{~N}\left[\mathrm{Br}_{2} \mathrm{~F}\right]$ were performed using density functional theory (DFT) implemented in the Amsterdam density functional package (ADF) (Fig. 1) [ 7 ].

The computations of the ground and excited states were carried out using ZORA Hamiltonian incorporating scalar relativistic corrections [ 8 ]. The triple- $\zeta$ Slater basis set plus two polarization functions (TZ2P) and the nonlocal correction for the exchange and correlation (XC), incorporated via the
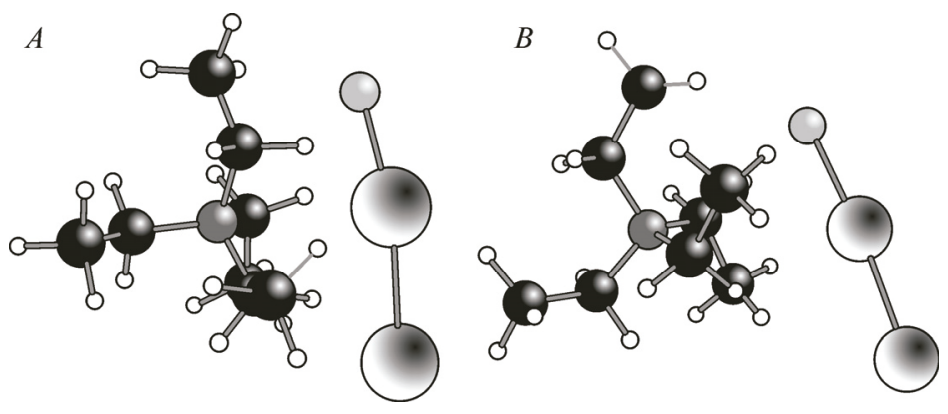

Fig. 1. The optimized structures of $\left(\mathrm{C}_{2} \mathrm{H}_{5}\right)_{4} \mathrm{~N}\left[\mathrm{I}_{2} \mathrm{~F}\right](A)$ and $\left(\mathrm{C}_{2} \mathrm{H}_{5}\right)_{4} \mathrm{~N}\left[\mathrm{Br}_{2} \mathrm{~F}\right](B)$ 
general gradient approximation (GGA) within the functional PBE-D3 [9], were employed. The molecular structures were fully optimized without symmetry constriction.

The excitation energies were estimated by the time dependent density functional theory (TDDFT [10 ]. This methodology is based on the linear response formalism within the iterative Davison procedure implemented in the ADF code. The calculations performed by first-principles method allowed us to calculate accurate excitation energies and oscillator strengths for the complexes.

\section{RESULTS AND DISCUSSIONS}

Vibrational analysis. For the vibrational analysis of both compounds, all of the expected bonds with assignements and experimental intensity are shown in Tables 1, 2 and Fig. 2. The calculated spectra were typically higher in enrgy than the experimental spectra due to the mixture of electron correlation effects [11].

After scaling down the calculated spectra, the experimental data correlated well with the calculated spectra. For $\left(\mathrm{C}_{2} \mathrm{H}_{5}\right)_{4} \mathrm{~N}\left[\mathrm{Br}_{2} \mathrm{~F}\right]$ and $\left(\mathrm{C}_{2} \mathrm{H}_{5}\right)_{4} \mathrm{~N}\left[\mathrm{I}_{2} \mathrm{~F}\right]$, the cation showed experimental vibration of $3421 \mathrm{~cm}^{-1}$ and $3431 \mathrm{~cm}^{-1}$, respectively. Vibrational analysis for the $\left(\mathrm{C}_{2} \mathrm{H}_{5}\right)_{4} \mathrm{~N}^{+}$cation for both compounds showed the vibrational stretching and bending of $\mathrm{CH}, \mathrm{CH}_{2}, \mathrm{CH}_{3}$ and $\mathrm{CN}$ groups.

Generally, the $\mathrm{C}-\mathrm{H}$ stretching characteristic frequency falls in the range of $3100-3000 \mathrm{~cm}^{-1}$ [12]. These compounds showed the $\mathrm{C}-\mathrm{H}$ stretching frequencies of $2853-3431 \mathrm{~cm}^{-1}$ [13]. The asymmetric $\mathrm{CH}_{2}$ stretching vibrations are usually observed under $3000 \mathrm{~cm}^{-1}$, which the symmetric stretch will appear between $3000 \mathrm{~cm}^{-1}$ and $2700 \mathrm{~cm}^{-1}$ [14,15]. Therefore the symmetric and asym-

$$
\text { T a b } 1 \text { e } 1
$$

T a b l e 2

The selected experimental and theoretical frequencies $\left(\mathrm{cm}^{-1}\right)$ and assignment of cation and anion of $\left(\mathrm{C}_{2} \mathrm{H}_{5}\right)_{4} \mathrm{~N}\left[\mathrm{I}_{2} \mathrm{~F}\right]$

\begin{tabular}{c|c|c|c}
\hline $\begin{array}{c}\text { Experi- } \\
\text { mental }\end{array}$ & $\begin{array}{c}\text { Theore- } \\
\text { tical }\end{array}$ & Vibration & $\begin{array}{c}\text { Intensity } \\
\text { (experimental) }\end{array}$ \\
\hline
\end{tabular}

\begin{tabular}{|c|c|c|c|}
\hline \multicolumn{4}{|c|}{$\left(\mathrm{C}_{2} \mathrm{H}_{5}\right)_{4} \mathrm{~N}^{+}$} \\
\hline 3421 & & $v_{\mathrm{CH} 2}+v_{19}$ & (w) \\
\hline 2976 & 2965 & $v_{\mathrm{CH} 2}+v_{8}$ & $0.7(\mathrm{~m})$ \\
\hline 2924 & 2934 & $v_{\mathrm{CH} 2}$, asym. str & $2.3(\mathrm{~m})$ \\
\hline 2853 & 2859 & $v_{13}, v_{\mathrm{CH} 2}$, asym. str & $72.3(\mathrm{~m})$ \\
\hline 2361 & & $v_{14}, \mathrm{CH}_{2}$, asym. str & (w) \\
\hline 1740 & & $v_{14}, v_{\mathrm{CH} 2}$, asym. str & (w) \\
\hline 1632 & & $v_{7}+v_{16}$ & (w) \\
\hline 1481 & & $v_{3}+v_{8}+v_{16}$ & (s) \\
\hline 1442 & & $v_{15}, \mathrm{CH}_{2}$, asym. def & (s) \\
\hline 1416 & 1375 & $v_{16}, \mathrm{CH}_{2}$, sym. str & $9.6(\mathrm{~s})$ \\
\hline 1169 & 1191 & $v_{\text {rock}}, \mathrm{CH}_{2}$, roking $v_{14}$ & $0.8(\mathrm{~s})$ \\
\hline 1051 & 1050 & $v_{18}, \mathrm{NC}_{4}$, asym. str & $1.0(\mathrm{~m})$ \\
\hline 482 & 488 & $v_{19}, \mathrm{NC}_{4}$, def. & $1.9(\mathrm{~m})$ \\
\hline 420 & 407 & $v_{19}, \mathrm{NC}_{4}$, def. & $2.4(\mathrm{~m})$ \\
\hline & & {$\left[\mathrm{I}_{2} \mathrm{~F}\right]^{-}$} & \\
\hline & 77 & Bending $\mathrm{I}-\mathrm{I}-\mathrm{F}$ & 12.3 \\
\hline & 121 & $v_{I-I}$ & 4.5 \\
\hline & 339 & $v_{I-F}$ & 139.9 \\
\hline
\end{tabular}

The selected experimental and theoretical frequencies $\left(\mathrm{cm}^{-1}\right)$ and assignment of cation and anion of $\left(\mathrm{C}_{2} \mathrm{H}_{5}\right)_{4} \mathrm{~N}\left[\mathrm{Br}_{2} \mathrm{~F}\right]$

\begin{tabular}{|c|c|c|c|}
\hline $\begin{array}{l}\text { Experi- } \\
\text { mental }\end{array}$ & $\begin{array}{c}\text { Theore- } \\
\text { tical }\end{array}$ & Vibration & $\begin{array}{c}\text { Intensity } \\
\text { (experimental) }\end{array}$ \\
\hline \multicolumn{4}{|c|}{$\left(\mathrm{C}_{2} \mathrm{H}_{5}\right)_{4} \mathrm{~N}^{+}$} \\
\hline 3431 & \multirow{5}{*}{2979} & $v_{\mathrm{CH} 2}+v_{19}$ & (m) \\
\hline 2984 & & $v_{\mathrm{CH} 2}+v_{8}$ & $10.0(\mathrm{~m})$ \\
\hline 2360 & & $v_{\mathrm{CH} 2}$, asym. str & (w) \\
\hline 1642 & & $v_{13}, v_{\mathrm{CH} 2}$, asym. str & (w) \\
\hline 1447 & & $v_{14}, \mathrm{CH}_{2}$ asym. str & (s) \\
\hline 1395 & 1379 & $v_{16}, \mathrm{CH}_{2}$, sym. str & $31.7(\mathrm{~m})$ \\
\hline 1299 & 1299 & $v_{\text {rock }}, \mathrm{CH}_{2}$, roking $v_{14}$ & $18.6(\mathrm{~m})$ \\
\hline 1176 & 1189 & $v_{14}, \mathrm{CH}_{2}$, asym. str & $0.8(\mathrm{~s})$ \\
\hline 1074 & 1087 & $v_{15}, \mathrm{CH}_{2}$, asym. def & $11.8(w)$ \\
\hline 1003 & 1006 & $v_{18}, \mathrm{NC}_{4}$, asym. str & $4.4(w)$ \\
\hline 483 & 495 & $v_{19}, \mathrm{NC}_{4}$, def. & $1.7(\mathrm{~m})$ \\
\hline 429 & 465 & $v_{19}, \mathrm{NC}_{4}$, def. & $0.9(\mathrm{w})$ \\
\hline \multicolumn{4}{|c|}{$\left[\mathrm{Br}_{2} \mathrm{~F}\right]^{-}$} \\
\hline & 134 & Bending $\mathrm{F}-\mathrm{Br}-\mathrm{Br}$ & 4.1 \\
\hline & 159 & $v_{\mathrm{Br}-\mathrm{Br}}$ & 24.3 \\
\hline & 312 & $v_{\mathrm{F}-\mathrm{Br}}$ & 166.1 \\
\hline
\end{tabular}

$\mathrm{w}=$ weak $; \mathrm{m}=$ medium; $\mathrm{s}=$ strong.

$\mathrm{w}=$ weak $; \mathrm{m}=$ medium $; \mathrm{s}=$ strong. 

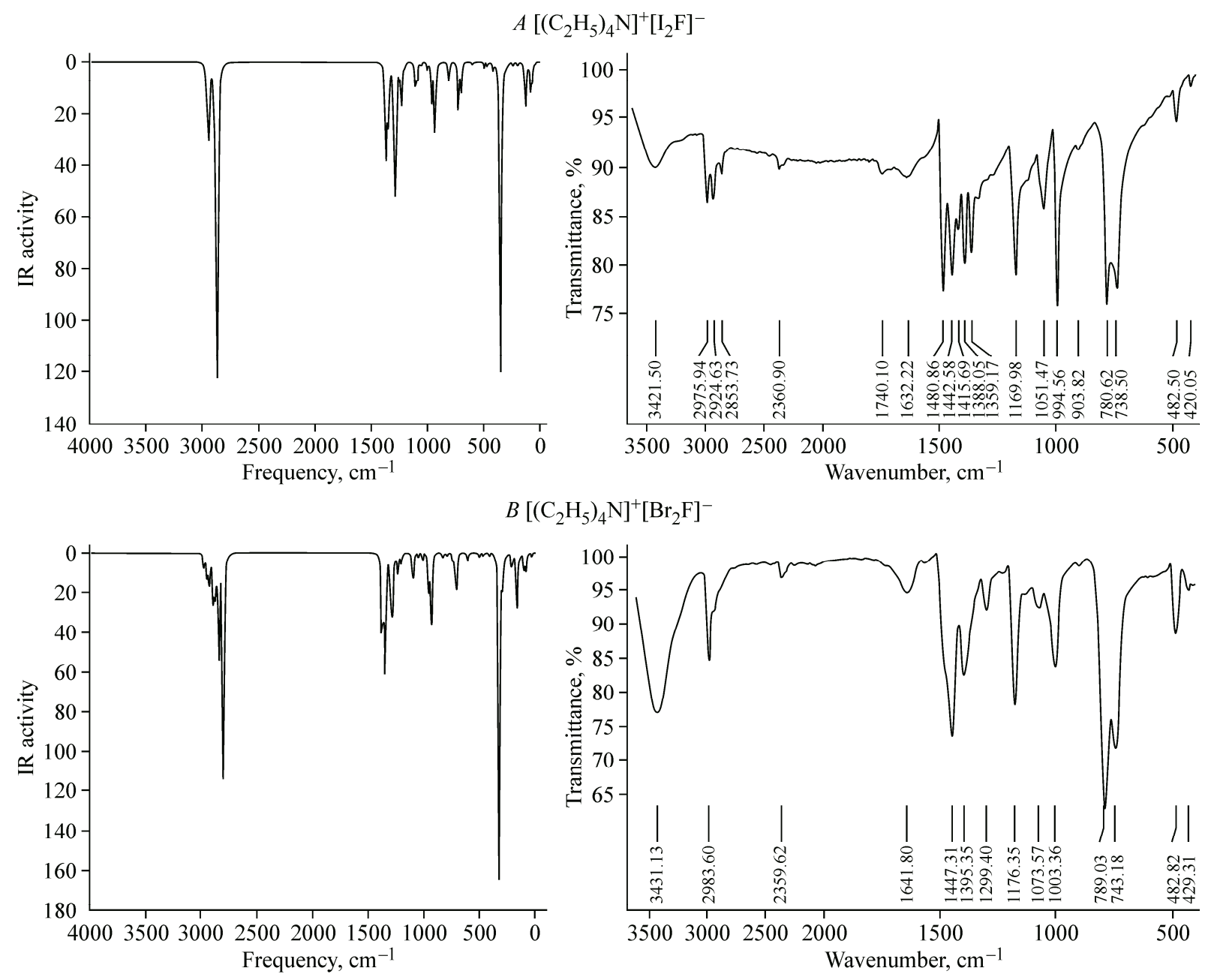

Fig. 2. Experimental and calculated FTIR spectra of the compounds

metric stretching wavelengths of $\mathrm{CH}_{3}$ are predictable near $2980 \mathrm{~cm}^{-1}$ and $2870 \mathrm{~cm}^{-1}$, respectively [16].

For $\left(\mathrm{C}_{2} \mathrm{H}_{5}\right)_{4} \mathrm{~N}\left[\mathrm{I}_{2} \mathrm{~F}\right]$ and $\left(\mathrm{C}_{2} \mathrm{H}_{5}\right)_{4} \mathrm{~N}\left[\mathrm{Br}_{2} \mathrm{~F}\right]$, the $\mathrm{CH}, \mathrm{CH}_{2}$ and $\mathrm{CH}_{3}$ experimental and calculated (in brackets) frequencies are $2853\{2859\} \mathrm{cm}^{-1}, 2924\{2934\} \mathrm{cm}^{-1}, 2976\{2965\} \mathrm{cm}^{-1}, 3421 \mathrm{~cm}^{-1}$ and $2984\{2979\} \mathrm{cm}^{-1}, 3431 \mathrm{~cm}^{-1}$, respectively, which show a good correlation between calculated and experimental observations $[17,18]$.

The $\mathrm{C}-\mathrm{C}$ bond vibrations occur within five ranges with variable intensity, and were observed at $1625-1590 \mathrm{~cm}^{-1}, 1590-1575 \mathrm{~cm}^{-1}, 1540-1470 \mathrm{~cm}^{-1}, 1465-1430 \mathrm{~cm}^{-1}$, and $1380-1280 \mathrm{~cm}^{-1}$, therefore the wavelengths at $1169\{1191\} \mathrm{cm}^{-1}, 1416\{1375\} \mathrm{cm}^{-1}, 1442 \mathrm{~cm}^{-1}, 1481 \mathrm{~cm}^{-1}, 1632 \mathrm{~cm}^{-1}$ for $\left(\mathrm{C}_{2} \mathrm{H}_{5}\right)_{4} \mathrm{~N}\left[\mathrm{I}_{2} \mathrm{~F}\right]$ and $1176\{1189\} \mathrm{cm}^{-1}, 1299\{1299\} \mathrm{cm}^{-1}, 1395\{1379\} \mathrm{cm}^{-1}, 1447 \mathrm{~cm}^{-1}, 1642 \mathrm{~cm}^{-1}$ for $\left(\mathrm{C}_{2} \mathrm{H}_{5}\right)_{4} \mathrm{~N}\left[\mathrm{Br}_{2} \mathrm{~F}\right]$ indicate that the calculated values show proximity with experimental values [19].

The assignement of $\mathrm{C}-\mathrm{N}$ vibrations is very difficult to determine because of the commixture of these modes with additional vibrations [20 ]. These vibrations, as specified by Silverstein [21] are in the range of $1382-1266 \mathrm{~cm}^{-1}$. For our cation part, the wavelengths observed were $420\{407\} \mathrm{cm}^{-1}$, $482\{488\} \mathrm{cm}^{-1}, 1051\{1050\} \mathrm{cm}^{-1}$ and $429\{465\} \mathrm{cm}^{-1}, 483\{495\} \mathrm{cm}^{-1}, 1003\{1006\} \mathrm{cm}^{-1}$ for the $\left(\mathrm{C}_{2} \mathrm{H}_{5}\right)_{4} \mathrm{~N}\left[\mathrm{I}_{2} \mathrm{~F}\right]$ and $\left(\mathrm{C}_{2} \mathrm{H}_{5}\right)_{4} \mathrm{~N}\left[\mathrm{Br}_{2} \mathrm{~F}\right]$, respectively, because in-plane bending and out-of plane bending modes occurred at lower frequencies than that recorded by Pathak et al. [22 ].

For the anions, three calculated vibrations occur between $77 \mathrm{~cm}^{-1}$ and $340 \mathrm{~cm}^{-1}$. Because the FTIR experimental range was from $400-4000 \mathrm{~cm}^{-1}$, we could not observe stretching and bending vibrations for the anionic part. 
Experimental and calculated (TD-DFT) electronic absorption spectra in the visible region (H indicates $\mathrm{HOMO}, \mathrm{L}$ indicates LUMO)

\begin{tabular}{|c|c|c|c|}
\hline $\begin{array}{l}\text { Experiment } \lambda, \mathrm{nm} \\
\varepsilon, \mathrm{dm}^{3} \cdot \mathrm{mol}^{-1} \cdot \mathrm{cm}^{-1} \text { a }\end{array}$ & $\begin{array}{c}\text { Theory } \\
\lambda, \mathrm{nm}(f)^{\mathrm{b}}\end{array}$ & $\begin{array}{l}\text { Transition } \\
\text { character }\end{array}$ & $\begin{array}{l}\text { Assignment of principal } \\
\text { transitions }{ }^{c}\end{array}$ \\
\hline \multicolumn{4}{|c|}{$\left(\mathrm{C}_{2} \mathrm{H}_{5}\right)_{4} \mathrm{~N}\left[\mathrm{I}_{2} \mathrm{~F}\right]$} \\
\hline \multirow[t]{5}{*}{$210(380)$} & $268(0.001)$ & $\pi \rightarrow \pi^{*}$ & \\
\hline & $271(0.002)$ & $A_{1} \rightarrow A_{1}{ }^{*}$ & $\mathrm{H}-3 \rightarrow \mathrm{L}(0.77)$ \\
\hline & $275(0.001)$ & & \\
\hline & $279(0.001)$ & & $\mathrm{H}-2 \rightarrow \mathrm{L}(0.49)$ \\
\hline & & & $\mathrm{H}-4 \rightarrow \mathrm{L}(0.03)$ \\
\hline \multirow[t]{3}{*}{294 (1850) } & $306(0.0003)$ & $n \rightarrow \pi^{*}$ & $\mathrm{H}-1 \rightarrow \mathrm{L}(0.97)$ \\
\hline & $321(0.001)$ & $A_{1} \rightarrow E^{*}$ & \\
\hline & $322(0.006)$ & & $\mathrm{H} \rightarrow \mathrm{L}(0.99)$ \\
\hline \multirow[t]{2}{*}{$396(980)$} & $434(0.004)$ & $\pi \rightarrow \pi^{*}$ & \\
\hline & $443(0.002)$ & $A_{1} \rightarrow E^{*}$ & \\
\hline \multicolumn{4}{|c|}{$\left(\mathrm{C}_{2} \mathrm{H}_{5}\right)_{4} \mathrm{~N}\left[\mathrm{Br}_{2} \mathrm{~F}\right]$} \\
\hline \multirow[t]{4}{*}{$218(120)$} & $250(0.0006)$ & $\pi \rightarrow \pi^{*}$ & \\
\hline & $251(0.003)$ & $E \rightarrow A_{1} *$ & $\mathrm{H}-1 \rightarrow \mathrm{L}+1$ \\
\hline & $256(0.0009)$ & & \\
\hline & $258(0.0009)$ & & $\mathrm{H} \rightarrow \mathrm{L}+1$ \\
\hline \multirow[t]{4}{*}{$271(1850)$} & $281(0.001)$ & $n \rightarrow \pi^{*}$ & \\
\hline & $283(0.001)$ & $A_{1} \rightarrow A_{1}^{*}$ & $\mathrm{H}-1 \rightarrow \mathrm{L}(0.99)$ \\
\hline & $288(0.002)$ & & \\
\hline & $290(0.002)$ & & $\mathrm{H} \rightarrow \mathrm{L}(0.99)$ \\
\hline \multirow[t]{2}{*}{$384(90)$} & $392(0.002)$ & $\pi \rightarrow \pi^{*}$ & \\
\hline & $395(0.001)$ & $A_{1} \rightarrow A_{1}^{*}$ & \\
\hline
\end{tabular}

\footnotetext{
${ }^{a}$ Experimental data recorded in solution in acetonitrile unless stated otherwise.

${ }^{\mathrm{b}}$ Calculated absorptions in the solid phase by TD-DFT, figures in parentheses indicate oscillator strength.

${ }^{\mathrm{c}}$ Calculated transition assignments in parentheses indicate fractional contribution to calculated absorption.
}

Electronic structure. The absorption spectra of both compounds were studied by the TDDFT method on the basis of the optimized ground state geometries. The oscillator strengths $(f)$, assignment and transition character are listed in Table 3 (Fig. 3). The absorptions at 210/218 nm, 294/271 nm, and $396 / 384 \mathrm{~nm}$ in the experimental spectra, and $271 / 258 \mathrm{~nm}, 322 / 290 \mathrm{~nm}$, and $434 / 392 \mathrm{~nm}$ in the calculated spectra were found for $\left(\mathrm{C}_{2} \mathrm{H}_{5}\right)_{4} \mathrm{~N}\left[\mathrm{I}_{2} \mathrm{~F}\right] /\left(\mathrm{C}_{2} \mathrm{H}_{5}\right)_{4} \mathrm{~N}\left[\mathrm{Br}_{2} \mathrm{~F}\right]$, respectively. The lowest calculated wavelengths were located at $271 \mathrm{~nm}(f=0.002)\}$ for $\left(\mathrm{C}_{2} \mathrm{H}_{5}\right)_{4} \mathrm{~N}\left[\mathrm{I}_{2} \mathrm{~F}\right]$ and $258 \mathrm{~nm}(f=0.009)$ for $\left(\mathrm{C}_{2} \mathrm{H}_{5}\right)_{4} \mathrm{~N}\left[\mathrm{Br}{ }_{2} \mathrm{~F}\right]$, and the transition characters for these wavelengths were $\pi \rightarrow \pi^{*}\left(A_{1} \rightarrow A_{1}^{*}\right)$ and $\pi \rightarrow \pi^{*}$ $\left(E \rightarrow A_{1}^{*}\right)$, respectively. The frontier orbital transition for the $271 / 258 \mathrm{~nm}$ was HOMO-3 $\rightarrow$ $\rightarrow$ LUMO/HOMO $\rightarrow$ LUMO+1 with $77 / 100 \%$ fractional contribution. All absorptions belong to $\pi \rightarrow \pi^{*}$ or $n \rightarrow \pi^{*}$ transitions. The comparison of experimental and calculated values showed a good correlation for both compounds [23, 24].

Frontier molecular orbitals. The frontier orbitals are HOMO and LUMO. We concentrated on the energy levels of these two orbitals because they are closest in energy. These orbitals are intimately involved in chemical reactivity, because they are the most readily available to electrophiles and 

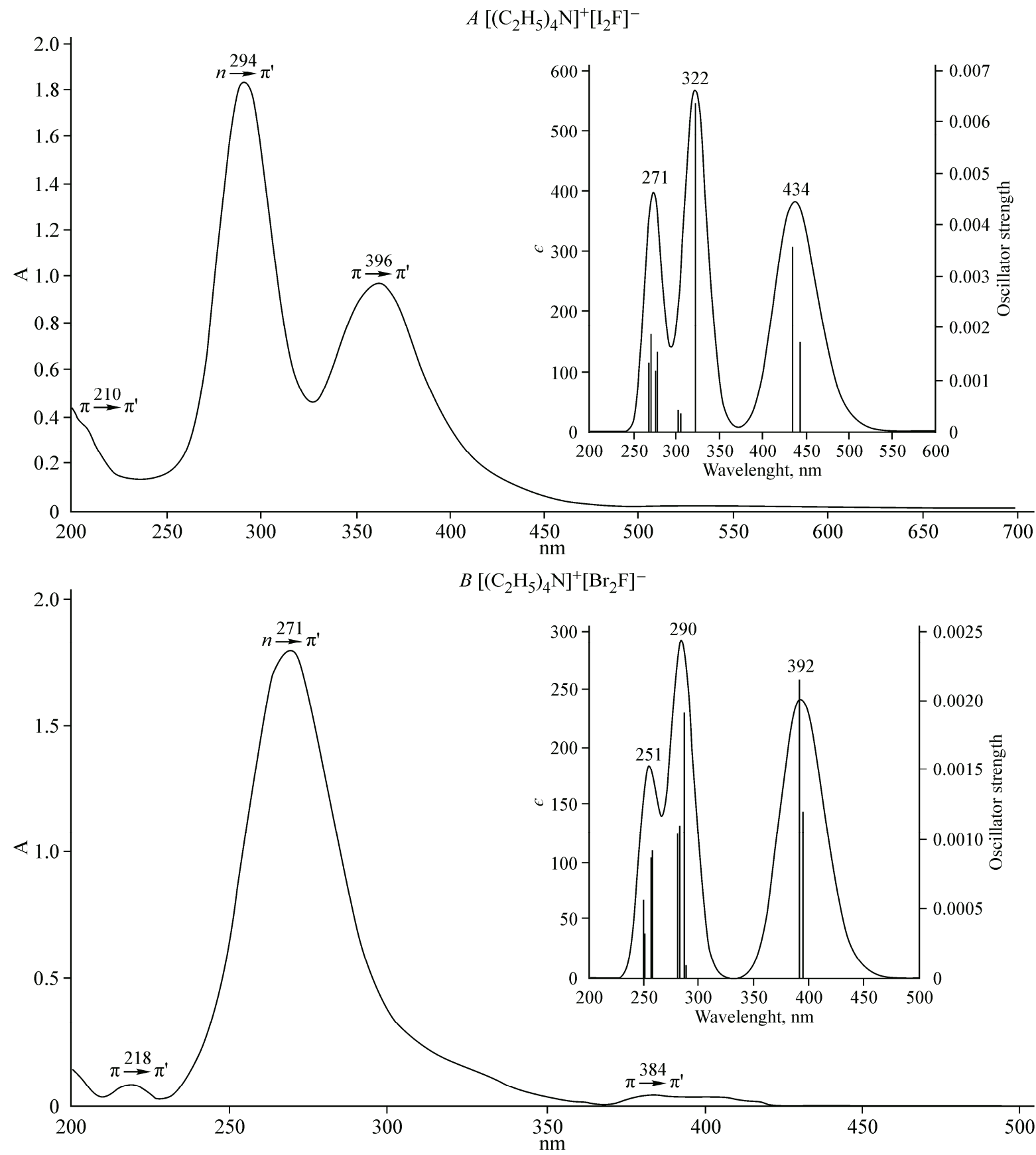

Fig. 3. Comparison between experimental and calculated UV-visible spectra

nucleophiles, respectively (Fig. 4) [25]. The HOMO represents the ability to donate an electron whereas LUMO is an electron acceptor and represents the ability to acquire an electron. This electronic absorption corresponds to the transition from the ground to the first excited state and is mainly described by one electron excitation from the highest occupied molecular orbital (HOMO). The highest occupied molecular orbital (HOMO) and lowest unoccupied molecular orbital (LUMO) are the main orbitals that determine chemical stability. While the energy of the HOMO is directly related to the ionization potential, the LUMO energy is directly related to electron affinity. Difference in energy between HOMO and LUMO orbitals is known as an energy gap, which is responsible for significant stability for the anions in tetraalkylammonium salts. 


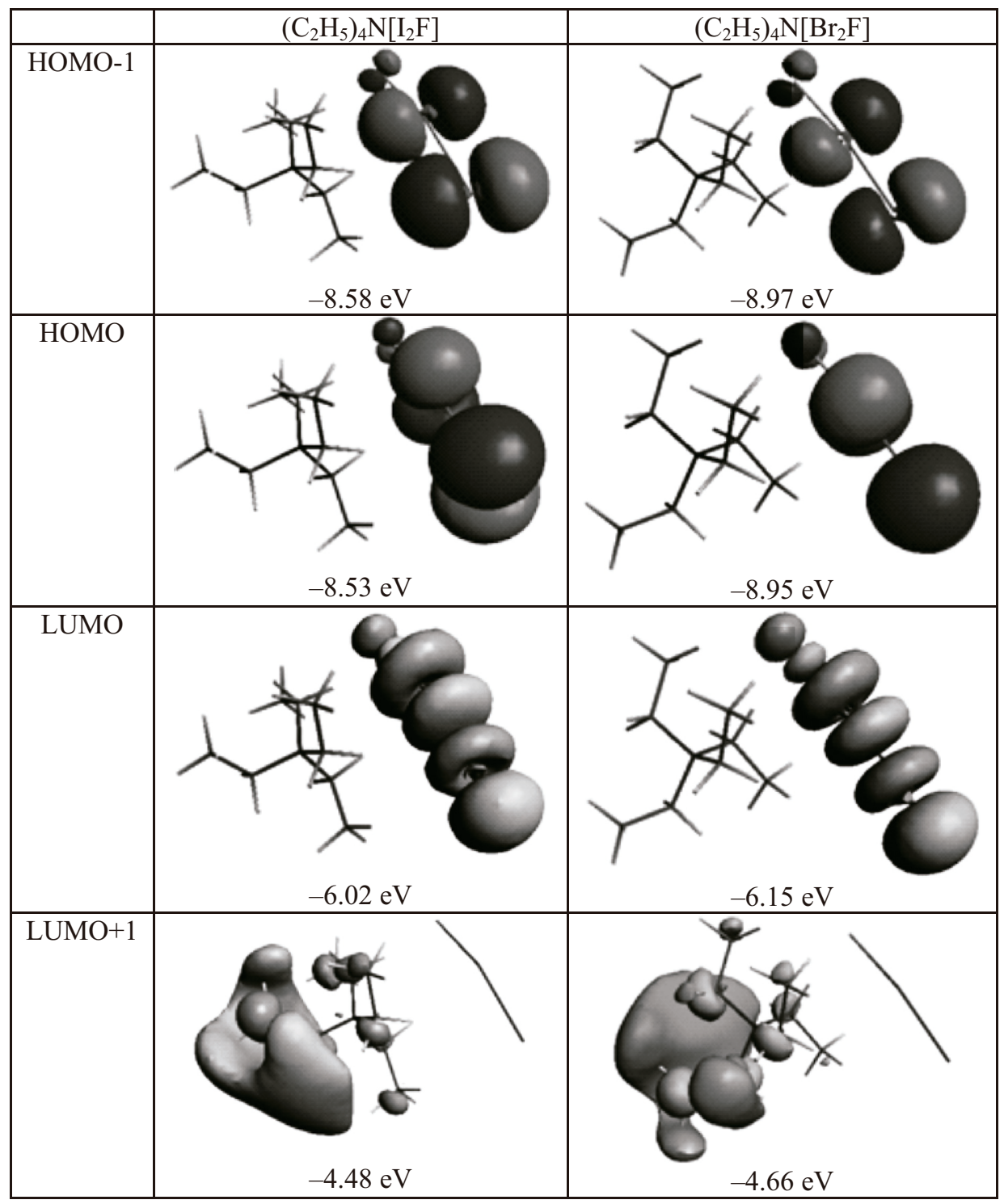

Fig. 4. Active molecular orbitals of $\left(\mathrm{C}_{2} \mathrm{H}_{5}\right)_{4} \mathrm{~N}\left[\mathrm{I}_{2} \mathrm{~F}\right]$ and $\left(\mathrm{C}_{2} \mathrm{H}_{5}\right)_{4} \mathrm{~N}\left[\mathrm{Br}{ }_{2} \mathrm{~F}\right]$ compounds with energy levels

These energies and energy gaps indicate closer energy states for both compounds. The TDOS of the compounds were calculated with the GaussSum 2.2 program, and are shown in Fig. 5. The TDOS plot shows the population study per orbital and validates a simple assessment of the character of the molecular orbitals [26-28 ]. Fig. 5 provides the perfect image of localization of charge in transmission band and valence band for both compounds with energy gaps $2.51 \mathrm{eV}$ for $\left(\mathrm{C}_{2} \mathrm{H}_{5}\right)_{4} \mathrm{~N}\left[\mathrm{I}_{2} \mathrm{~F}\right]$ and $2.8 \mathrm{eV}$ for $\left(\mathrm{C}_{2} \mathrm{H}_{5}\right)_{4} \mathrm{~N}\left[\mathrm{Br}_{2} \mathrm{~F}\right]$. These energy gaps imply that $\left(\mathrm{C}_{2} \mathrm{H}_{5}\right)_{4} \mathrm{~N}\left[\mathrm{I}_{2} \mathrm{~F}\right]$ would be more reactive than $\left(\mathrm{C}_{2} \mathrm{H}_{5}\right)_{4} \mathrm{~N}\left[\mathrm{Br}_{2} \mathrm{~F}\right][29]$.

\section{CONCLUSIONS}

Two tetraethylammonium salts $\mathrm{I}_{2} \mathrm{~F}^{-}, \mathrm{Br}_{2} \mathrm{~F}^{-}$were synthesized in one step and characterized by elemental analysis, IR and UV-Vis techniques. Preparation of these compounds showed the ability of the tetraethylammonium salts to halide addition to main group element compounds. Optimized geometry parameters were calculated at ADF-ZORA level. The theoretical calculations agreed well with the experimental results. Electronic and vibrational spectra of these new fluoro-compounds were studied. 

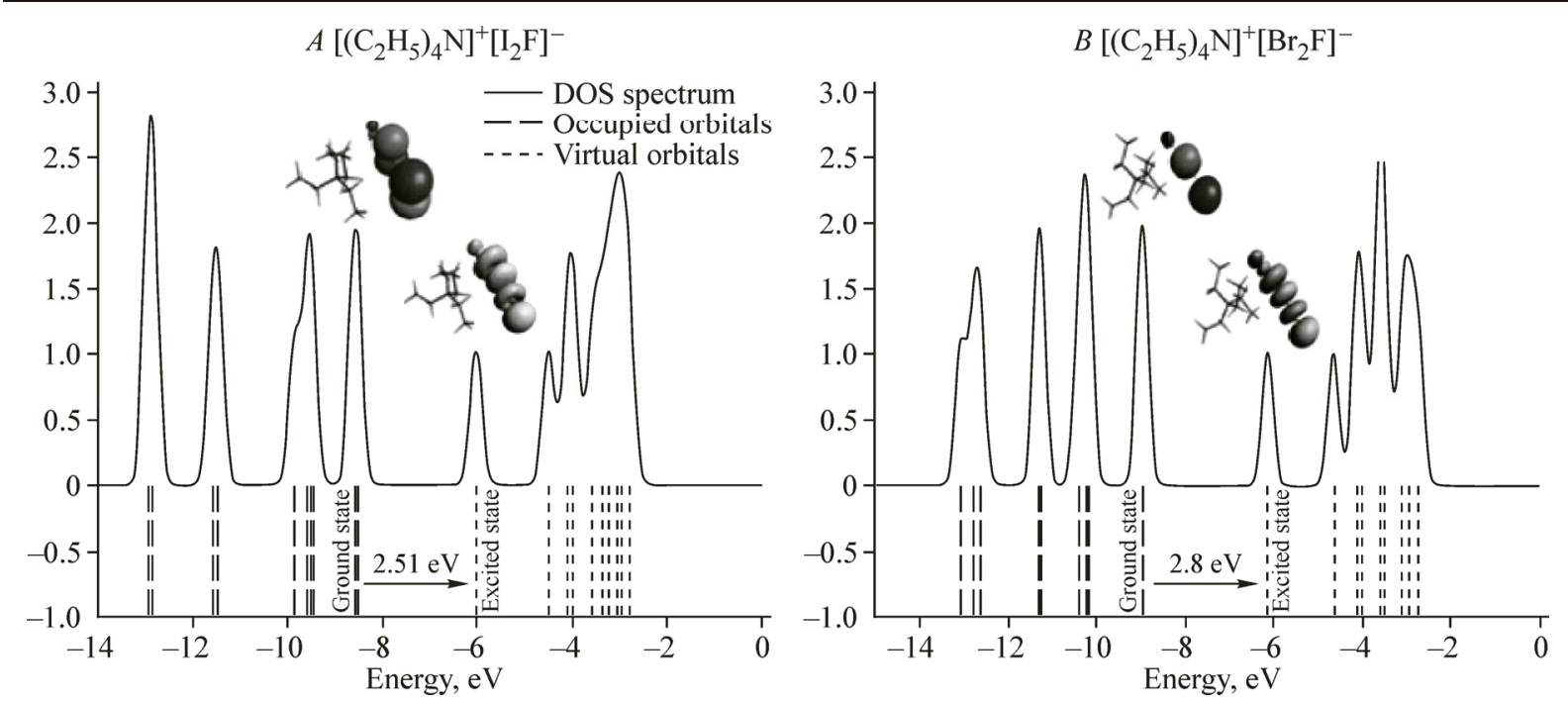

Fig. 5. Total density of state (TDOS) plot for orbital analysis

In the vibrational spectrum of $\left(\mathrm{C}_{2} \mathrm{H}_{5}\right)_{4} \mathrm{~N}\left[\mathrm{I}_{2} \mathrm{~F}\right] \mathrm{HOMO}, \mathrm{HOMO}-1$, LUMO, LUMO+1 orbitals and TDOS plots with energy levels were obtained for both compounds. The comparison of the energy gaps shows that the reactivity of $\left(\mathrm{C}_{2} \mathrm{H}_{5}\right)_{4} \mathrm{~N}\left[\mathrm{I}_{2} \mathrm{~F}\right]$ would be higher than $\left(\mathrm{C}_{2} \mathrm{H}_{5}\right)_{4} \mathrm{~N}\left[\mathrm{Br}_{2} \mathrm{~F}\right]$.

We gratefully acknowledge the financial support from the Research Council of Imam Khomeini International University, Universidad Bernardo O'Higgins, Universidad Andrés Bello and RRT Fondecyt 11130007.

\section{REFERENCES}

1. Mahjoub A.R., Ghamrnami S., Abbasi A.R., Hossainian A. // Indian J. Chem. - 2000. - 39A. - P. 434 - 435.

2. Mahjoub A.R., Ghamrnami S., Abbasi A.R., Hossainian A. // J. Chem. Res. - 2000. - S10. - P. 486 - 487.

3. Giese S., Seppelt K. // Angew. Chem. Int. Ed. Engl. - 1994. - 33. - P. 461 - 463.

4. Javanshir Z., Mehrani Kh., Ghammamy Sh., Saghatforoush L., Seyedsadjadi S., Hassanijoshaghani S., Tavakol H. // Bull. Korean Chem. Soc. - 2008. - 29. - P. 1461 - 1464.

5. Ghammamy S., Anvarnia Z., Jafari M., Mehrani K., Tavakol H., Javanshir Z., Rezaeibehbahani G. // Main Gr. Chem. - 2009. - 8. - P. $299-306$.

6. Christe K.O., David A.D., Helene P.A., Jeremy C.P. // J. Am. Chem. Soc. - 1994. - 116, N 7. - P. 2850 2858.

7. Velde G.T., Bickelhaupt F.M., Baerends E.J., Fonseca Guerra C., van Gisbergen S.J.A., Snijders J.G., Ziegle T. // J. Comput. Chem. - 2001. - 22. - P. 931 - 967.

8. Ghammamy Sh., Rezaeibehbehani G.R. // J. Inorg. Chem. - 2005. - 50. - P. 1671 - 1682.

9. Gao W., Feng H., Xuan X., Chen L. // J. Mol. Model. - 2012. - 18. - P. 4577 - 4589.

10. Casida M.E., Huix-Rotllant M. // Annu. Rev. Phys. Chem. - 2012. - 63. - P. 287 - 323.

11. Pathak S.K., Srivastava R., Sachan A.K., Prasad O., Sinha L., Asiri A.M., Karabacak M. // Spectrochim. Acta, Part A. - 2015. - 135. - P. $283-295$.

12. Socrates G. Infrared and Raman Characteristic Group Frequencies. - 3rd ed. - New York: Wiley, 2001.

13. Moorth P.P., Gunasekaran S., Swaminathan S., Ramkumaar G.R. // Spectrochim. Acta, Part A. - 2015. - 137. - P. $412-422$.

14. Litvinov G. In: Proceeding of the XIII International Conference on Raman Spectroscopy. - Wurzburg, Germany, 1992.

15. Furic K., Mohacek V., Bonifacic M., Stefanic I. // J. Mol. Struct. - 1992. - 267. - P. 39 - 44.

16. Kleinman D.A. // Phys. Rev. - 1962. - 126. - P. 1977 - 1979.

17. Sert Yu., Singer L.M., Findlater M., Doğan Hatice, Çırak Ç. // Spectrochim. Acta, Part A. - 2014. - 128. - P. $46-53$. 
18. Premkumar S., Jawahar A., Mathavan T., Kumara Dhas M., Sathe V.G., Milton Franklin Benial A. // Spectrochim. Acta, Part A. - 2014. - 129. - P. $74-83$.

19. Sas E.B., Kose E., Kurt M., Karabacak M. // Spectrochim. Acta, Part A. - 2015. - 137. - P. 1315 - 1333.

20. Luque F.J., Orozco M., Bhadane P.K., Gadre S.R. // J. Phys. Chem. - 1993. - 97. - P. 9380 - 9384.

21. Silverstein R.M., Bassler G.C., Morrill T.C. // Spectrometric Identification of Organic Compounds. - 3rd ed. - New York: John Wiley \& Sons, 1974.

22. Pathak S.K., Srivastava R., Sachan A.K., Prasad O., Sinha L., Asiri A.M., Karabacak M. // Spectrochim. Acta, Part A. - 2015. - 135. - P. 283-295.

23. Han D., Liu J., Miao R., Zhao L., Zhang G. // Polyhedron. - 2015. - 85. - P. 506 - 510.

24. Ding W.-L., Wang D.-M., Geng Z.-Y., Zhao X.-L., Xu W.-B. // Dyes Pigm. - 2013. - 98. - P. 125 - 135.

25. Reshak A.H., Azam S. // Int. J. Electrochem. Sci. - 2013. - 8. - P. 10396 - 10423.

26. Nagarajan V., Chandiramouli R. // Comput. Theor. Chem. - 2014. - 1049. - P. 20 - 27.

27. Pathak S.K., Srivastava R., Sachan A.K., Prasad O., Sinha L., Asiri A.M., Karabacak M. // Spectrochim. Acta, Part A. - 2015. - 135. - P. 283 - 295.

28. Sas E.B., Kose E., Kurt M., Karabacak M. // Spectrochim. Acta, Part A. - 2015. - 137. - P. 1315 - 1333.

29. Nagarajan V., Chandiramouli R. // Comput. Theor. Chem. - 2014. - 1049. - P. 20 - 27. 